\title{
Сверхминиатюрные излучатели на основе полупроводниковых наноструктур
}

В.А. Гайслер ${ }^{1}$, И.А. Деребезов ${ }^{1,2}$, А.В. Гайслер ${ }^{1}$, Д.В. Дмитриев ${ }^{1}$, А.И. Торопов ${ }^{1}$

${ }^{1}$ Институт физики полупроводников им. А.В. Ржанова, Новосибирск, 630090, пр. Академика Лаврентьева 13

2 Сибирский государственный университет телекоммуникаций и информатики, Новосибирск, 630102, ул. Кирова 86

тел:+7 (383)3306945, факс:+7 (383)3306945, эл. почта: haisler@isp.nsc.ru

DOI 10.34077/RCSP2021-23

В докладе будет представлен краткий обзор результатов, полученных в ИФП СО РАН, в области разработки сверхминиатюрных излучателей на основе одиночных квантовых точек (КТ) и лазеров с вертикальным резонатором (ЛВР) для миниатюрных квантовых стандартов частоты (КСЧ).

Исследована система КТ на основе твердых растворов $\mathrm{Al}_{y} \mathrm{In}_{1-y} \mathrm{As} / \mathrm{Al}_{x} \mathrm{Ga}_{1-x} \mathrm{As}$. Использование широкозонных твердых растворов $\mathrm{Al}_{y} \mathrm{In}_{1-y} \mathrm{As}$ в качестве основы КТ позволяет существенно расширить спектральный диапазон излучения в коротковолновую область, включая участок длин волн вблизи 770 нм, представляющий интерес для разработки аэрокосмических систем квантовой криптографии.
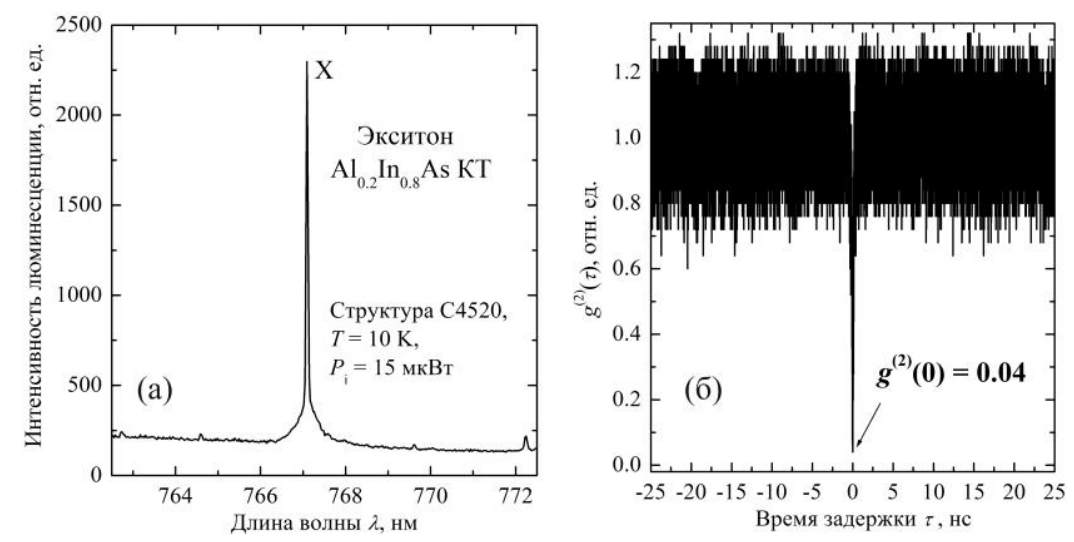

Разработана и реализована конструкция микрорезонаторов для излучателей одиночных фотонов на основе $\mathrm{Al}_{x} \mathrm{Ga}_{1-x} \mathrm{As}$ зеркал и $\mathrm{Al}_{y} \mathrm{In}_{1-y} \mathrm{As} \mathrm{KT}$.

С использованием интерферометра Хэнбери Брауна Твисса исследована статистика излучения одиночных $\mathrm{Al}_{y} \mathrm{In}_{1-y} \mathrm{As}$ КТ (рис. 1). Функция парных фотонных корреляций отчетливо демонстрирует субпуассоновский характер статистики излучения $\left(g^{(2)}(0)=0.04\right)$, что является прямым подтверждением перспективности использования разработанных микрорезонаторов для создания эффективных излучателей одиночных фотонов на основе $\mathrm{Al}_{y} \mathrm{In}_{1-y} \mathrm{As}$ KT в спектральном диапазоне 0.77 мкм.

Разработаны и изготовлены одномодовые лазеры с вертикальным резонатором с длиной волны генерации 894.6 нм для использования в миниатюрных квантовых стандартах частоты на основе $\mathrm{Cs}^{133}$ и лазеры с длиной волны 794.8 нм для КСЧ на основе $\mathrm{Rb}^{87}$ (рис. 2).

Точная подстройка длины волны под резонанс с $\mathrm{Cs}$ и $\mathrm{Rb}$ осуществляется путем изменения температуры и тока накачки лазеров.

Характеристики лазеров соответствуют требованиям, предъявляемым к излучателям в миниатюрных квантовых стандартах частоты.
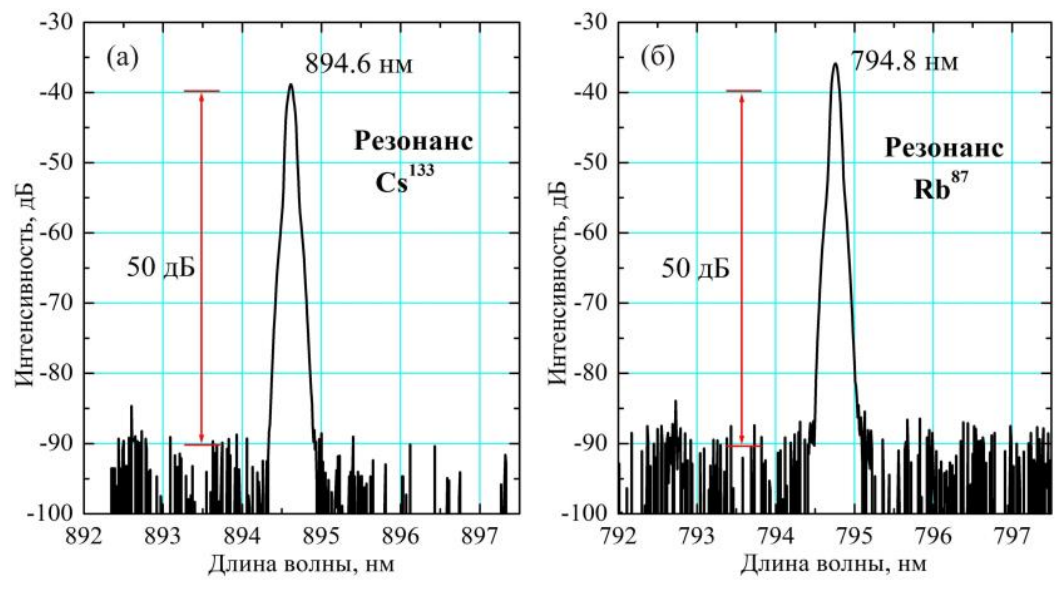

Рис.2. Спектры ЛВР для КСЧ на основе Cs (a) и Rb (б). 